\title{
Studies on the Effect of Salts on the Channel Activity of Kissper, a Kiwi Fruit Peptide
}

\author{
Daniela Meleleo*, Enrico Gallucci, Gabriella Notarachille, Cesare Sblano, Alessandra Schettino \\ and Silvia Micelli
}

\author{
Department of Biosciences, Biotechnologies and Pharmacological Sciences, University of Bari "Aldo Moro", via \\ E.Orabona 4, 70126 Bari, Italy
}

\begin{abstract}
Fruits and vegetables are known to possess health benefits: indeed, they contain a large number of bioactive molecules with a positive impact on human health. Dietary proteins possess specific biological properties which make these components potential ingredients of functional or health-promoting foods. Many of these properties are attributed to physiologically-active peptides encrypted in protein molecules.

Kissper, a 39-residue peptide isolated from kiwi fruit (Actinidia deliciosa), derives from the processing of kiwellin, a well-represented novel allergenic protein present in the edible part of the fruit. Kissper has six cysteine residues forming three disulfide bridges. This cysteine pattern is similar, but not identical, to those observed in some plant and animal proteins, including toxins involved in defence mechanisms. We show that kissper forms ion channels in DOPS:DOPE:POPC PLMs in different media, such as $\mathrm{KCl}$, potassium gluconate, potassium citrate and potassium phosphate monobasic. Kissper's channels show a strong voltage dependence in all media used, and an estimated pore diameter in the range from 1.9 to $7.6 \AA$ in $\mathrm{KCl}$ medium. Finally, kissper's pores shift selectivity from anions to neutral to cations, depending on the nature of the salt solutions. Therefore we propose the kissper as a novel nutraceutical component of kiwi fruit that may have a positive impact on human health due to its channel-like pathways which modulate membrane permeability. The kissper action might promote the adsorption of substances, in particular, within the gastrointestinal tract, helping digestion, preventing constipation and harmful accumulation of metabolites.
\end{abstract}

Keywords: Channel diameter, ion channel, Kissper, planar lipid membrane, pore-forming peptide.

\section{INTRODUCTION}

Fruits and vegetables have long been known to possess health benefits, as well as serving as a source of energy. Leaves, stems, and fruit have all been used to cure various ailments in human beings. Plant products, especially small fruits, are exceptionally rich in a large number of bioactive molecules with a positive impact on human health. In fact, plants produce a diverse range of bioactive molecules, making them a rich source of various medicinal products. Research into bioactive substances might lead to the discovery of new compounds. Although several studies have provided strong evidence that fruit and vegetable consumption can improve human health, the nature of the bioactive molecules involved - and their mechanism of action - have not yet been elucidated. Bioactive molecules are components of food that possess biological activity in addition to their nutritional value.

Kiwi fruit has significant positive effects on human health. Numerous data suggest the presence of biological activities associated with kiwi fruit extracts such as in vitro cytotoxicity for tumor cell lines and antimicrobial activity [1], protection against oxidative DNA damage $[2,3]$, cardio-

*Address correspondence to this author at the Department of Biosciences, Biotechnologies and Pharmacological Sciences, University of Bari "Aldo Moro", via E. Orabona 4, 70126 Bari, Italy; Tel: +390805442775;

E-mail:dmeleleo@farmbiol.uniba.it vascular protective properties [4-6], anti-hyperglycemic activity [7] and immunostimolatory activity [8,9]. These benefits seem to depend on the action of a range of medicinally useful compounds such as vitamin C, polyphenols, carotenoids, flavonoids, minerals and others [10-12] which the Kiwi fruit has in abundance. Furthermore, some authors have reported that kiwi fruit peel extracts show cytotoxic activity [13]. Recent studies describe the beneficial effects of kiwi fruit on intestinal functions [14-16] confirming the numerous anecdotal reports on the laxative properties of the kiwi fruit. These advantages are ascribed to its rich dietary fiber content $(3.4 \mathrm{~g} / 100 \mathrm{~g})$, although other constituents may contribute partly to its laxative effect. One of the novel compounds in kiwi fruit that has been suggested to interact in laxation is actinidin [15].

In this study we focus on Kissper, a 39-residue peptide isolated from kiwi fruit (Actinidia deliciosa).

It derives from the processing of kiwellin, a wellrepresented novel allergenic protein present in the edible part of the fruit [17]. Its isolation and purification processes and its structural characterization were reported in our previous study [18].

The primary structure of kissper shows the highest identity $(69 \%)$ with $\mathrm{N}$-terminal regions of both the putative kiwellin of potato leaves and the cDNA-derived sequence of Gripp 22 from grape, and lower identity (31-47\%) with 
regions of several peptides and proteins having a variety of functions, such as toxins, protease inhibitors and proteins containing the EGF-like cysteine-rich motif [18]. Kissper has six cysteine residues forming three disulfide bridges (Cys4-Cys36, Cys8-Cys20, Cys14-Cys25). The analysis of structural data reveals that the peptide is characterized by the presence of multiple conformations. In fact, the analysis of NOESY data indicates that the peptide conformation is consistent with the presence of a $\beta$-hairpin with the two short $\beta$-strands encompassing Ile19-Ile21 and Lys24-Asn26, connected through a central loop centered on Lys22-Gly23. Moreover, the residues Gly32-Ile35 are involved in a short helix [18].

However, the presence of cysteine residues makes kissper similar to peptides and proteins displaying the socalled EGF-like cysteine-rich motif, such as mammalian fibrillins, human endothelins and antimicrobial peptides. Recent studies describe structural similarities between polypeptides showing EGF-like motifs and pore-forming peptides, including thionins and defensins.

On interacting with membrane lipids, these peptides can form membrane pores, that can ultimately result in disruption of the cell membrane and leakage to death [19]. On the other hand, pore formation is not the only mechanism of microbial killing. Several observations suggest that translocated peptides can alter cytoplasmic membrane septum formation, inhibit cell-wall, nucleic-acid and protein synthesis or enzymatic activity [20].

In this work, we report a systematic investigation of the interaction of Kissper with PLMs in different salt solutions, in the hope to elucidate the mechanisms involved in the beneficial effects of kiwi on human health, suggesting its pharmacological and biotechnological applicability. In particular, we monitored the kissper channel current in lipid bilayer membranes (PLMs) made up of dioleoylphosphatidylserine:dioleoyl-phosphatidylethanolamine:palmitoyl-oleoyl-phosphatidylcholine (DOPS:DOPE:POPC), a surrogate of intestinal membrane, in different salt solutions, i.e. $\mathrm{KCl}$, potassium gluconate, potassium citrate and potassium phosphate monobasic $(1 \mathrm{M}, \mathrm{pH}=7)$, substances involved in some physiological processes such as acid-base status, control of carbohydrate metabolism or energy balance, as well as in disease prevention [21].

\section{MATERIALS AND METHODS}

\section{Single Channel Measurement}

PLMs made up of DOPS:DOPE:POPC (27:27:18, $\mathrm{w}: \mathrm{w}: \mathrm{w})$ in $1 \% \mathrm{n}$-decane (Fluka) were formed as previously described $[18,22]$. The channel current was monitored in different salt solutions, i.e. $\mathrm{KCl}$, potassium gluconate, potassium citrate and potassium phosphate monobasic (Fluka) $1 \mathrm{M}$ at $\mathrm{pH} 7.0$, and at $22 \pm 1^{\circ} \mathrm{C}$. The salts used in the experiments were of analytical grade.

A solution of Kissper (produced by Prof Ciardiello) was prepared by dissolving Kissper powder in bidistilled sterile water at $\mathrm{pH}$ 3.8. From this solution, different solutions at scalar concentrations were prepared, stocked and stored at $20{ }^{\circ} \mathrm{C}$ until use.

The lipid-peptide mixture was prepared by withdrawing and diluting $5 \mu \mathrm{l}$ of kissper solution at a concentration of
$96 \mathrm{pM}$ in $50 \mu \mathrm{l}$ of lipid mixture to obtain the final concentration of $9.6 \mathrm{pM}$ under stirring for 3 minutes. The incubation lasted five hours until the bilayer formed. Before use, the lipid-peptide mixture was carefully stirred for 3-4 min. Bilayers were painted across a $0.3 \mathrm{~mm}$ diameter of a small circular hole in a teflon divider separating two $4 \mathrm{ml}$ teflon chambers. The membrane current was monitored with an oscilloscope and recorded on a chart recorder for further data analysis by hand. The cis and trans chambers were connected to the amplifier head stage by $\mathrm{Ag} / \mathrm{AgCl}$ electrodes in series with a voltage source and a highly sensitive current amplifier. The single-channel instrumentation had a time resolution of 1-10 ms, depending on the magnitude of the single-channel conductance. The cis-side compartment, where kissper was present, had a positive polarity. A transnegative potential (indicated by a minus sign) means that a negative potential was applied to the trans side, the compartment opposite the one where Kissper was present.

\section{Data Analysis}

Membrane capacitance was calculated using a calibration curve obtained by simulating the membrane capacitance with a discrete set of capacitances of known values, $\mathrm{Cn}$, and measuring the corresponding output voltage, Vlh. The data obtained were fitted by the formula:

$$
\mathrm{Y}=\mathrm{A} \times \mathrm{X} /(\mathrm{B}+\mathrm{X})
$$

in which $\mathrm{Y}$ and $\mathrm{X}$ correspond to Vlh and $\mathrm{Cn}$ respectively, while $\mathrm{A}$ and $\mathrm{B}$ are free parameters to be estimated by the fitting procedures. The values of parameters A and B were used to transform the Vlh value into capacitance data, as described by Micelli et al. [23].

The single-channel data were obtained from at least three and sometimes five experiments (more than 100 single channels for each experiment) performed on different days. A histogram of the conductance amplitude distribution for each experiment was constructed and fitted by a Gaussian distribution function (Graph Pad Prism ${ }^{\mathrm{TM}}$ version 3.0; Graph Pad Software, Inc, http://www.graphpad.com). Results are expressed as central conductance \pm standard error $\left(\Lambda_{c} \pm S E\right)$ and were evaluated by analysis of variance (ANOVA-Tukey test). A value of $\mathrm{P}<0.05$ was considered significant. The ANOVA test, F-test and the fitting procedures were performed using the GraphPad Prism 3 software (GraphPad Prism $^{\mathrm{TM}}$ version 3.0; GraphPad Software, Inc, http://www. graphpad.com).

To estimate the size of the Kissper channel, we used the conductance fluctuations $(\Lambda)$ of the conductance amplitude distribution, and channel diameter was calculated with the formula:

$$
\Lambda=\left(\sigma \times \pi \times \mathrm{r}^{2}\right) / \mathrm{d}
$$

where $\Lambda$ is the conductance, $\sigma$ is the specific conductibility of the solution filling the channel, $r$ is the channel radius, $d$ is the channel length and $\pi$ has the value of 3.14. Assuming that a cylindrical channel with a length (d) of $6 \mathrm{~nm}$ (corresponding to the membrane thickness) is filled with a solution of the same specific conductibility $(\sigma)$ as the external medium, the channel diameter $(\mathrm{d}=2 \mathrm{r})$ can be estimated [24, 25]. 
To identify the charge on the ion carrying the current, we measured the shift in the reversal potential induced by a change from a symmetrical to an asymmetrical salt solution system. When the membrane conductance reached a virtually stable value, a concentration gradient was set, with $1 \mathrm{M}$ on the cis side and $0.5 \mathrm{M}$ on the trans side. The reversal potential was determined by I-V curve, when the measured amplitude of the channel events at each potential was used.

The permeability ratio was calculated using the Goldman-Hodgkin-Katz equation:

$$
\mathrm{V}=(\mathrm{RT} / \mathrm{F}) * \ln \left\{\left(\mathrm{P}_{\mathrm{K}}[\mathrm{K}]_{\mathrm{t}}+\mathrm{P}_{\mathrm{Cl}}[\mathrm{Cl}]_{\mathrm{c}}\right) /\left(\mathrm{P}_{\mathrm{K}}[\mathrm{K}]_{\mathrm{c}}+\mathrm{P}_{\mathrm{Cl}}[\mathrm{Cl}]_{\mathrm{t}}\right)\right\}
$$

where $[\mathrm{X}]_{\mathrm{t}}$ and $[\mathrm{X}]_{\mathrm{c}}$ are the concentrations of the ion species $\mathrm{X}$ in the trans and cis compartments, respectively; where R,
$\mathrm{T}$ and $\mathrm{F}$ are respectively molar gas constant, thermodynamic temperature and Faraday constant.

\section{RESULTS}

\section{Effect of Different Salt Solutions on Kissper Channel Conductance}

First of all, to exclude any non-specific and destabilizing effect of different salt solutions per se on the PLMs used, we performed experiments with the lipid mixture only. The stability of the PLM was tested by applying a voltage of $\pm 100 \mathrm{mV}$ for six hours and monitoring constant values for conductance $(25 \mathrm{pS})$ and capacitance $\left(0,26 \mu \mathrm{F} / \mathrm{cm}^{2}\right)$. The different salt solutions caused no variations in membrane conductance and capacitance when using bare membranes.
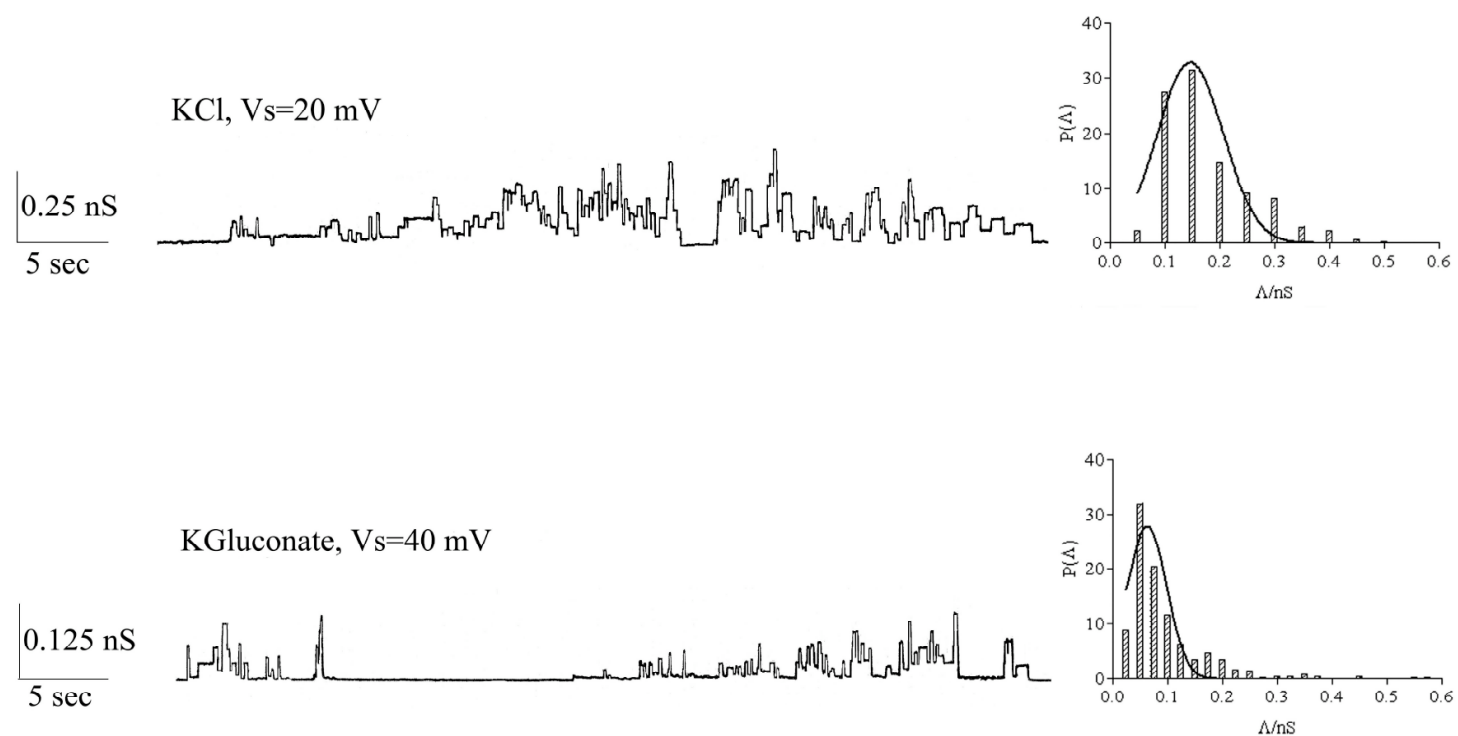

KCitrate, $\mathrm{Vs}=40 \mathrm{mV}$
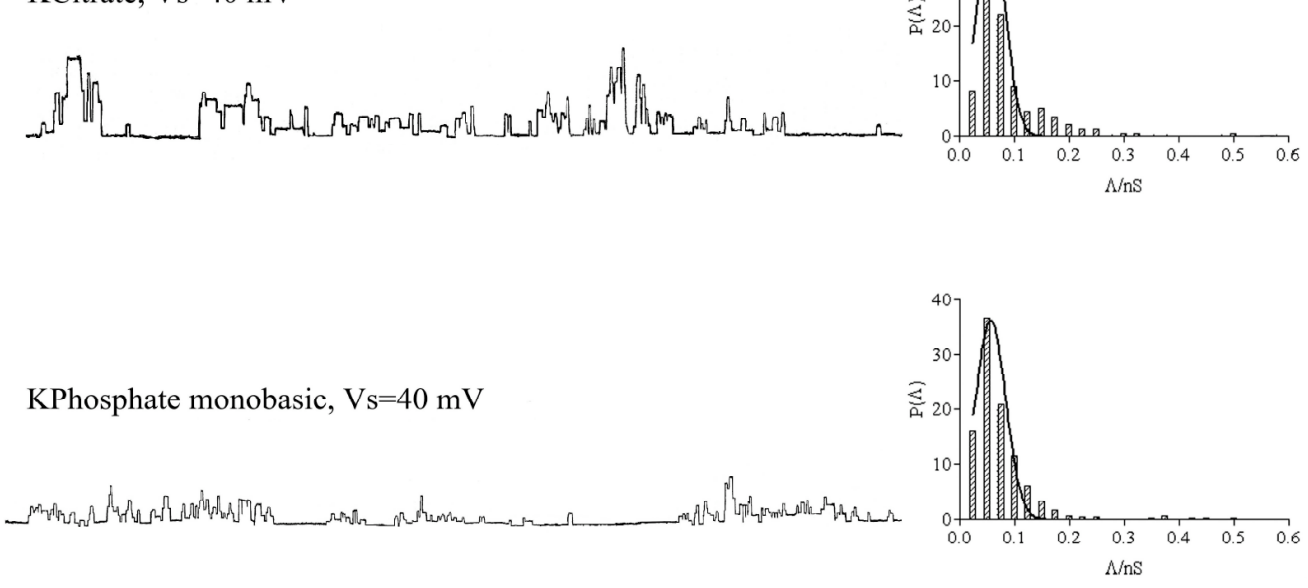

Fig. (1). Kissper channel activity in DOPS:DOPE:POPC PLM. Representative Kissper channel incorporated into DOPS:DOPE:POPC PLMs in the different salt solutions. Each trace represents a fragment of the recording of the activity obtained in individual experiments. Experimental conditions: $\mathrm{KCl} 1 \mathrm{M}$, Kissper $9.6 \mathrm{pM}, \mathrm{pH} 7$, temperature $22{ }^{\circ} \mathrm{C}$. The applied voltages indicated for each trace are the activation voltages. Amplitude histograms of the channel conductance for each trace are shown next to their respective traces. 
The experiments to monitor kissper channel activity were carried out with a lipid-peptide mixture prepared as described (see Materials and Methods). After membrane formation, in all of the different media used, non-random events could be observed that fluctuated between conductive and non-conductive states compatible with channel-type openings and closures with different conductance levels and frequency, indicating Kissper incorporation into the PLM and channel formation. Furthermore, we observed alternating periods of bursting channel activity followed by quiescent periods in which a return of the current to the baseline was observed. Fig. (1) shows examples of chart recordings of the channel activity with associated distribution histograms in different salt solutions where the open events are seen to predominate over the terminating events (channels).

The activation time, i.e. the time at which the first conductance variation is evident after membrane formation with the lipid-peptide mixture, was about $2 \mathrm{~min}$ in $\mathrm{KCl}$ or 15 min in potassium gluconate, citrate or phosphate monobasic.

The activation voltage, i.e. the lowest applied voltage that induces channel-like activity across the membrane, was $20 / 40 \mathrm{mV}$ when $\mathrm{KCl} /$ potassium gluconate, citrate or phosphate monobasic was used, respectively. After activation, the channel activity continued in the range \pm 20 $\pm 60 \mathrm{mV}$ of applied voltage. For applied voltages higher than $\pm 60 \mathrm{mV}$, the channel activity was paroxystic with the result that the membrane, after a high rate of channel formation, became destabilized.

All single-channel events were used to calculate the channel amplitudes. Conductance amplitude distribution analysed in different experiments revealed the existence of one main conductance level. The central value of conductance $\left(\Lambda_{\mathrm{c}}\right)$ obtained by the Gaussian best-fit characterizes the conductance state of Kissper channel in the various salt solutions used.

Fig. (2) reports the central value of $\Lambda_{c} \pm \mathrm{SE}$ at the different applied voltages for different experimental conditions in DOPS:DOPE:POPC PLMs. One interesting aspect is that the $\Lambda_{\mathrm{c}}$ values show a strong voltage dependence in all media used. In fact, $\Lambda_{c}$ decreases with increases in the applied voltages.
If we compare the $\Lambda_{c}$ values at each applied voltage for the media used, the results indicate that the $\Lambda_{\mathrm{c}}$ values:

- in potassium chloride, are not significantly different at applied voltages of $\pm 20, \pm 40$ and $\pm 60 \mathrm{mV}$, indicating a symmetry of kissper channel conductance;

- in potassium gluconate, are not significantly different at low applied voltages $( \pm 20$ and $\pm 40 \mathrm{mV} ; \mathrm{P}=0.3444$ and 0.3088 respectively) but are significantly different $(\mathrm{P}=0.0235)$ at the higher applied voltage $( \pm 60 \mathrm{mV})$;

- in potassium citrate, are not significantly different at an applied voltage of $\pm 20 \mathrm{mV}(\mathrm{P}=0.8856)$ whereas, at applied voltages of 40 and $60 \mathrm{mV}$, the $\Lambda_{\mathrm{c}}$ values are significantly higher $(\mathrm{P}=0.0619$ and $<0.0001$ respectively) than the respective negative applied voltage, indicating an asymmetry of kissper channel conductance;

- in potassium phosphate monobasic, are not significantly different at an applied voltage of $\pm 20 \mathrm{mV}(\mathrm{P}=0.1717)$, whereas, they are significantly higher at applied voltages of -40 and $-60 \mathrm{mV}(\mathrm{P}=0.0645$ and 0.0055 , respectively) than the respective positive applied voltages, indicating an asymmetry of kissper channel conductance;

Finally, the $\Lambda_{\mathrm{c}}$ values at applied voltages of $\pm 20 \mathrm{mV}$ ( $\mathrm{P}=$ $<0.0001 / 0.0021$ at $20 /-20 \mathrm{mV}$ respectively) are significantly higher in $\mathrm{KCl}$ than for the other salts.

\section{Effect of Different Salt Solutions on Kissper Channel Frequency}

The kissper frequency, i.e. the number of openings in a period of $60 \mathrm{sec}$, is determined for different experimental conditions in DOPS:DOPE:POPC PLMs.

Table 1 reports the mean values of frequency \pm standard deviation at the different applied voltages and with the different media used.

In $\mathrm{KCl}$, the frequency values are random at different applied voltages. The channel activity of kissper destabilized the membrane until rupture. However, the mean frequency at negative applied voltages is higher than that obtained at positive applied voltages.

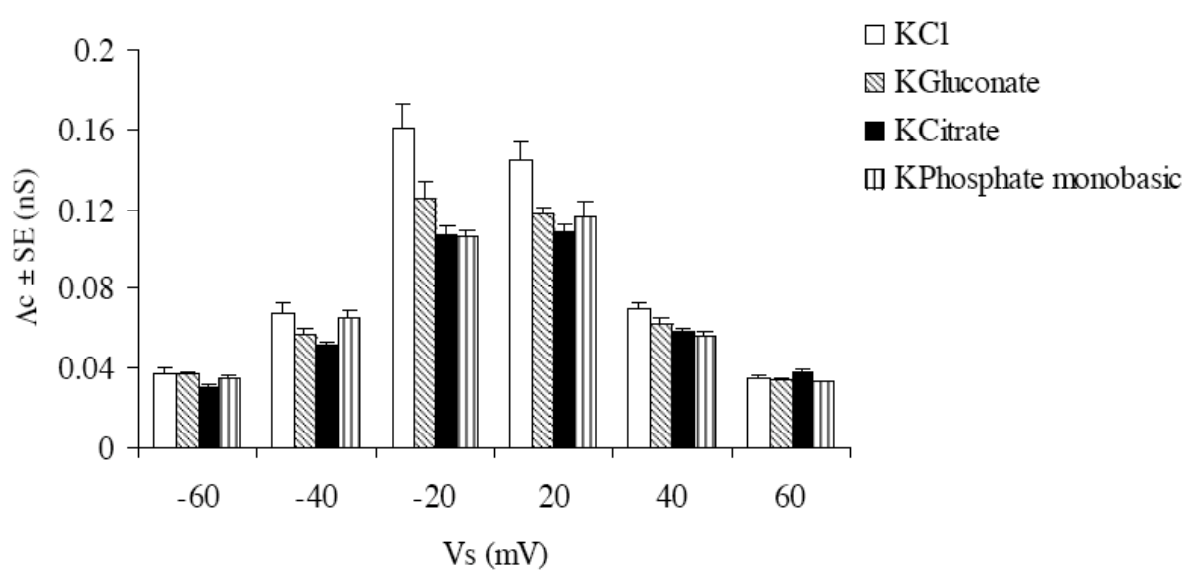

Fig. (2). Conductance central values of Kissper channel in DOPS:DOPE:POPC PLM. $\Lambda_{\mathrm{c}} \pm$ SE of Kissper channel in the different salt solutions. The minimum and maximum number of channels considered $(\mathrm{N})$ out of a total number of channels considered $(\mathrm{Nt}) \mathrm{was}$ : $\mathrm{KCl}$, $130<\mathrm{N}<461, \mathrm{Nt}=1962 ;$ KGluconate, $256<\mathrm{N}<575, \mathrm{Nt}=2542 ;$ KCitrate, $118<\mathrm{N}<436, \mathrm{Nt}=1568 ;$ KPhosphate monobasic, $120<\mathrm{N}<508, \mathrm{Nt}=1545$. 
Table 1. Kissper Channel Frequency in DOPS:DOPE:POPC PLM

\begin{tabular}{|c|c|c|c|c|}
\hline & KCl & KGluconate & KCitrate & KPhosphate monobasic \\
\hline $\begin{array}{c}\text { Vs } \\
(\mathrm{mV})\end{array}$ & $\begin{array}{c}\text { Frequency } \pm \mathrm{SD} \\
\text { (events/min) }\end{array}$ & $\begin{array}{c}\text { Frequency } \pm \text { SD } \\
\text { (events/min) }\end{array}$ & $\begin{array}{c}\text { Frequency } \pm \text { SD } \\
\text { (events/min) }\end{array}$ & $\begin{array}{c}\text { Frequency } \pm \text { SD } \\
(\text { events } / \text { min) }\end{array}$ \\
\hline 60 & $3.92 \pm 0.34$ & $6.10 \pm 0.38$ & $18.63 \pm 0.92$ & $9.00 \pm 0.40$ \\
\hline 40 & $11.05 \pm 0.64$ & $8.41 \pm 0.35$ & $12.30 \pm 0.70$ & $10.67 \pm 1.02$ \\
\hline 20 & $7.76 \pm 0.47$ & $14.87 \pm 0.63$ & $13.64 \pm 0.18$ & $8.72 \pm 0.27$ \\
\hline Mean & $7.58 \pm 0.12$ & $9.79 \pm 0.12$ & $5.89 \pm 0.54$ & $7.76 \pm 0.60$ \\
\hline-20 & $13.05 \pm 0.61$ & $12.92 \pm 0.55$ & $4.14 \pm 0.35$ & $14.42 \pm 0.66$ \\
\hline-40 & $9.00 \pm 0.45$ & $10.69 \pm 0.74$ & $7.01 \pm 0.56$ & $18.32 \pm 1.92$ \\
\hline-60 & $11.83 \pm 0.59$ & $9.28 \pm 0.49$ & $5.68 \pm 0.10$ & $13.50 \pm 0.61$ \\
\hline Mean & $11.29 \pm 0.07$ & $10.96 \pm 0.11$ & \\
\hline
\end{tabular}

Values represent the frequency of kissper events \pm SD and the mean values of frequency $\pm \mathrm{SD}$ (in bold) at different applied voltages and with different media used.

In potassium gluconate, the frequency decreases with increases in the applied voltage; in fact, in this condition we found alternating periods of channel activity followed by long quiescent periods. However, there was no difference in mean frequencies at positive and negative applied voltages.

In potassium citrate, the frequency increases on increasing the applied voltages. However, the mean frequency is higher at positive than the negative applied voltages. This result indicates that the turnover of kissper pores at positive applied voltages is better than at negative applied voltages.

In potassium phosphate monobasic, the occurrence decreases with the increase in the positive applied voltage. Besides, the occurrence mean value at negative applied voltages is higher than that obtained at positive applied voltages. This result indicates that the turnover of kissper pores at negative applied voltages is better than at positive applied voltages.

\section{Effect of Different Salt Solutions on Kissper-Channel Ion Selectivity}

The ion selectivity of kissper channels in DOPS:DOPE: POPC PLMs in the different salt solutions used was determined by means of an I-V relationship at different transmembrane potentials under asymmetrical solution conditions (see Methods section).

The reversal potential was determined using the I-V curves, when the measured amplitude of the channel events at each potential was used; the reversal potential was $6.24,0.60,-7.73,0.75 \mathrm{mV}$ in $\mathrm{KCl}$, potassium gluconate, citrate and phosphate monobasic, respectively (Fig. 3). The permeability ratio $\left(\mathrm{P}_{\text {cation }} / \mathrm{P}_{\text {anion }}\right)$, calculated using the Goldman-Hodgkin-Katz equation, was 0.47, 0.93, 2.62, 0.92 for $\mathrm{KCl}$, potassium gluconate, citrate and phosphate monobasic respectively, indicating that the ion selectivity of the Kissper channel shifts from anions to neutral to cations, in relation to the salt solution used.

\section{Estimation of the Kissper Channel Dimensions}

Estimation of the Kissper channel dimensions, although rough, is based on studies of ion conductance through the bilayer (see Materials and methods). The conductance fluctuations were not uniform in size but distributed over the same range $(0,05-0.90 \mathrm{nS}$ at applied voltages of $\pm 20 \mathrm{mV})$ for all different salt solutions used in this study (Fig. 4). Therefore, the Kissper channel diameters were calculated when $\mathrm{KCl}(\sigma=9.9803 \mathrm{~S} / \mathrm{m})$ was used as medium facing the membrane and at the lower applied voltage in which the channel activity of Kissper was detectable, i.e. $\pm 20 \mathrm{mV}$. The diameter values were in the range of 1.9 to $6.2 \AA$ at an applied voltage of $20 \mathrm{mV}$ and of 1.9 to $7.6 \AA$ at an applied voltage of $-20 \mathrm{mV}$. The pore diameter values for the other three salt solutions are similar to those obtained in $\mathrm{KCl}$ at the same applied voltages.

\section{DISCUSSION}

In recent years, many proteins and peptides from food have been found to be physiologically active beyond their purely nutritional value. Many dietary proteins possess specific biological properties which make them potential ingredients of functional or health-promoting foods. Many of these properties are attributed to physiologically-active peptides encrypted within food proteins, with a view to utilizing such peptides as functional food ingredients for health maintenance.

Bioactive peptides have been defined as "food-derived components (genuine or generated) that, in addition to their nutritional value exert a physiological effect in the body" [26]. These bioactive peptides are usually $2-20$ amino acid residues in length, although some have been reported to be $>20$ amino acid residues long. Bioactive peptides may be absorbed through the intestine where they subsequently enter the circulatory system intact to exert various physiological effects, or they may produce local effects in the digestive tract [27].

Many peptides of plant and animal origin with relevant bioactive potential have been discovered from different sources such as milk, eggs, meat, fish, soy, wheat rice, broccoli, corn and barley [28, 29]. For these bioactive peptides and proteins, a wide range of activities has been described, including antimicrobial and antifungal properties, blood pressure-lowering effects, cholesterol-lowering ability, 

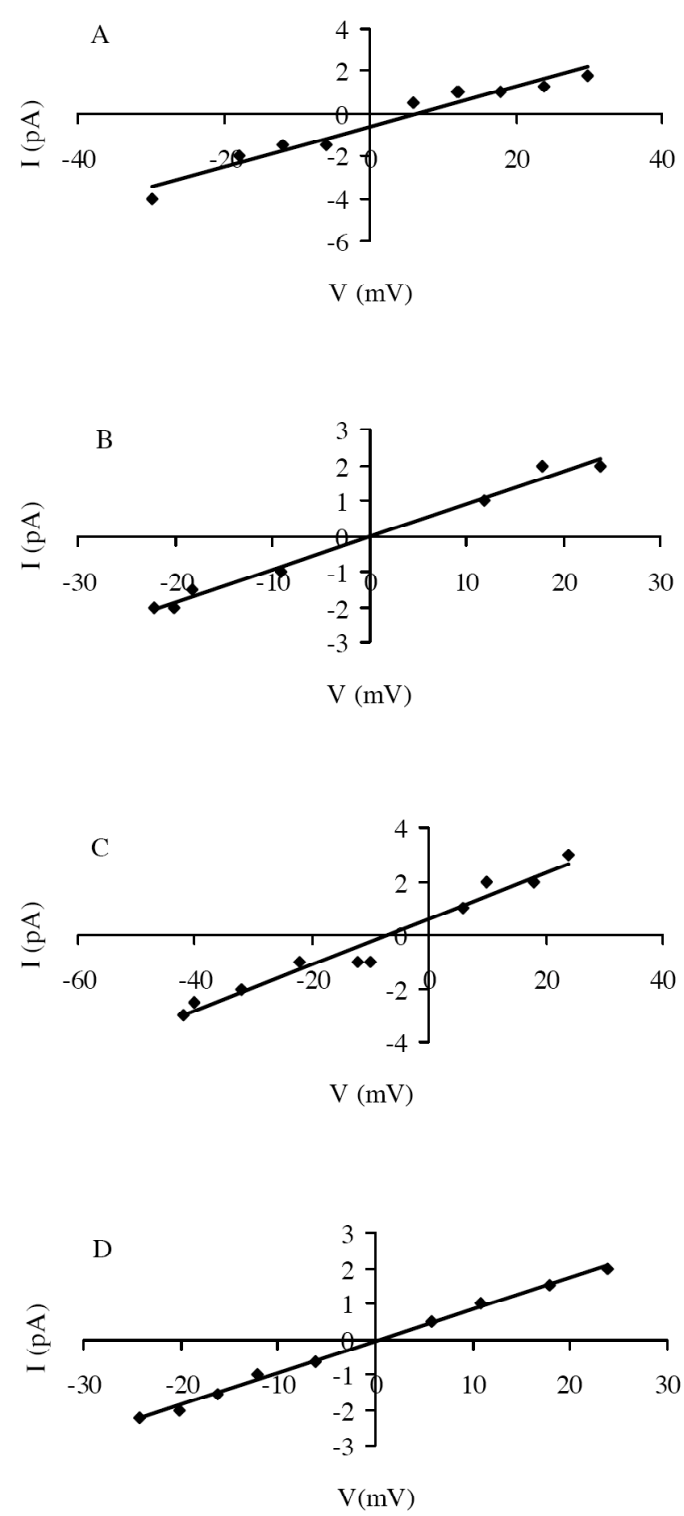

Fig. (3). Kissper channel ion selectivity in DOPS:DOPE:POPC PLM. Kissper channel selectivity in the different salt solutions. The amplitude of the channel current (pA) is plotted as a function of the transmembrane potential $(\mathrm{mV})$. Conductance was determined by linear regression of the current values in asymmetrical solutions $1 \mathrm{M} / 0.5 \mathrm{M}$ cis/trans of different salts used: $\mathrm{KCl}$ (A), KGluconate (B), KCitrate (C), KPhosphate monobasic (D). Intercept was used to calculate $\mathrm{P}_{\mathrm{K}}^{+} / \mathrm{P}_{\mathrm{Cl}}^{-}$.

antithrombotic effects, enhancement of mineral absorption, immunomodulatory effects, opioid activities and localized effects on the gut [28].

Although several studies on the mechanism of action of bioactive peptides have been carried out, the relationships between structural properties and functional activities have not been completely elucidated. The most widely reported bioactive peptides display antihypertensive activity, that seems to depend on their inhibitory effect on angiotensin 1converting enzyme (ACE), a dipeptidyl carboxypeptidase found in various tissues in the body and integral to the moderation of blood pressure and normal heart function [27].
Opioid peptides exert their activity by binding to specific receptors on the target cell, while individual receptors are responsible for specific physiological effects [30].

Mineral-binding peptides increase passive calcium transport in the distal small intestine, as found by some authors [31]. Antioxidants are known to be beneficial to human health, as they may protect the body against molecules known as reactive oxygen species (ROS), which can attack membrane lipids, protein and DNA [27]. Several studies in vitro and in vivo have demonstrated the high antioxidant activity of kiwifruit [32].

Antimicrobial peptides have been identified in a range of foods to date: the antimicrobial activity of many bioactive peptides is expressed by permeabilizing the membranes of microorganisms, either in a detergent-like manner or by making well-structured channels, thus compromising the electrochemical gradient and other cell functions. The most plentiful source of these peptides are milk proteins, including the caseins and lactoferrin [27]. Other antimicrobial peptides from different sources have been discovered such as thionins from monocotyledonous and dicotyledonous plants with antifungal activity [33], scorpion neurotoxins (60-70 amino acid residues) that modulate ion channel conductance in excitable tissues by depolarising membrane potential, insect and scorpion defensins (37-40 amino acids long) that disrupt membrane integrity by forming pores [34], six $\alpha$-defensins and two $\beta$-defensins identified in humans that exhibit microbicidal activity [35], and the human endothelins (21 amino acids long) that bind to the endothelin receptor, generating calcium currents in cells.

All these peptides display sequence diversity, various lengths and different tri-dimensional structures, but all these compounds exhibit commonality at different levels:

1) Bioactivity - they interact with membrane receptors, or block ion channels or disrupt the membrane permeability by forming pores;

2) Structure - the structure of the peptides reveals that they share a similar cysteine-stabilized $\alpha$-helical motif which involves a Cys---Cys stretch of the $\alpha$-helix bonded through disulfide bridges to a $\beta$-strand.

The kissper peptide seems to have primary and secondary structures similar to peptides showing EGF-like motifs. The first result of this study shows that the kissper peptide forms ion channels in DOPS:DOPE:POPC PLMs in $\mathrm{KCl}$, potassium gluconate, potassium citrate and potassium phosphate monobasic. The channel activity of Kissper might depend on hydrophobic and hydrophilic interactions of the Kissper molecules with membrane lipids, as suggested for some bioactive peptides. This result is confirmed by our previous study in which we showed that kissper interacts with lipid bilayers forming channel-like pores with anion selectivity in $\mathrm{KCl}$ [18].

In this study, we show that kissper peptide pores are permeable to gluconate, citrate and phosphate monobasic as well as to $\mathrm{Cl}^{-}$. The molecular volume of gluconate, citrate and phosphate monobasic is higher than that of $\mathrm{Cl}^{-}$ (www.molinspiration.com), indicating that the kissper pore is large enough to allow the transit of gluconate, citrate and phosphate. The pore diameter values and heterogeneity of 
$\mathrm{KCl}$
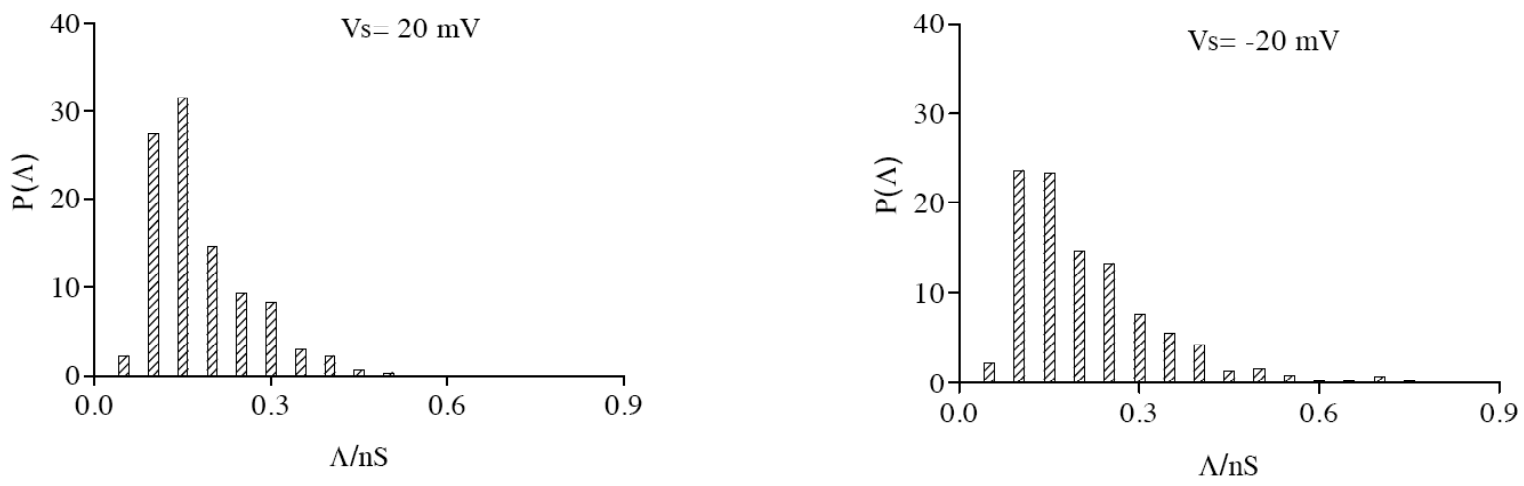

\section{KGluconate}
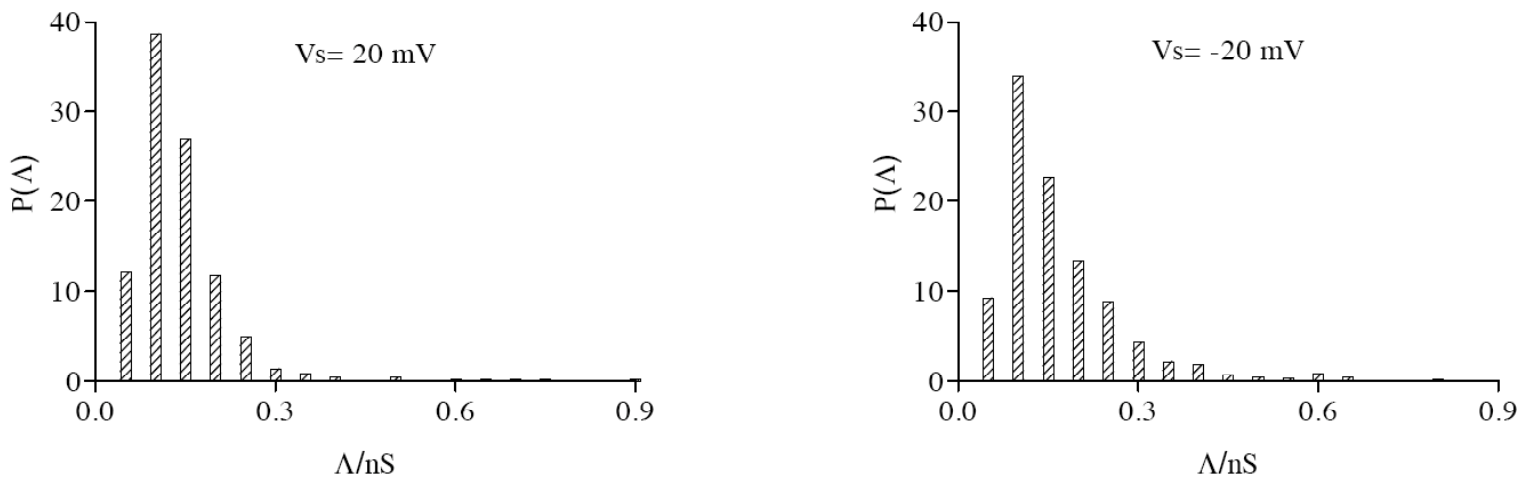

KCitrate
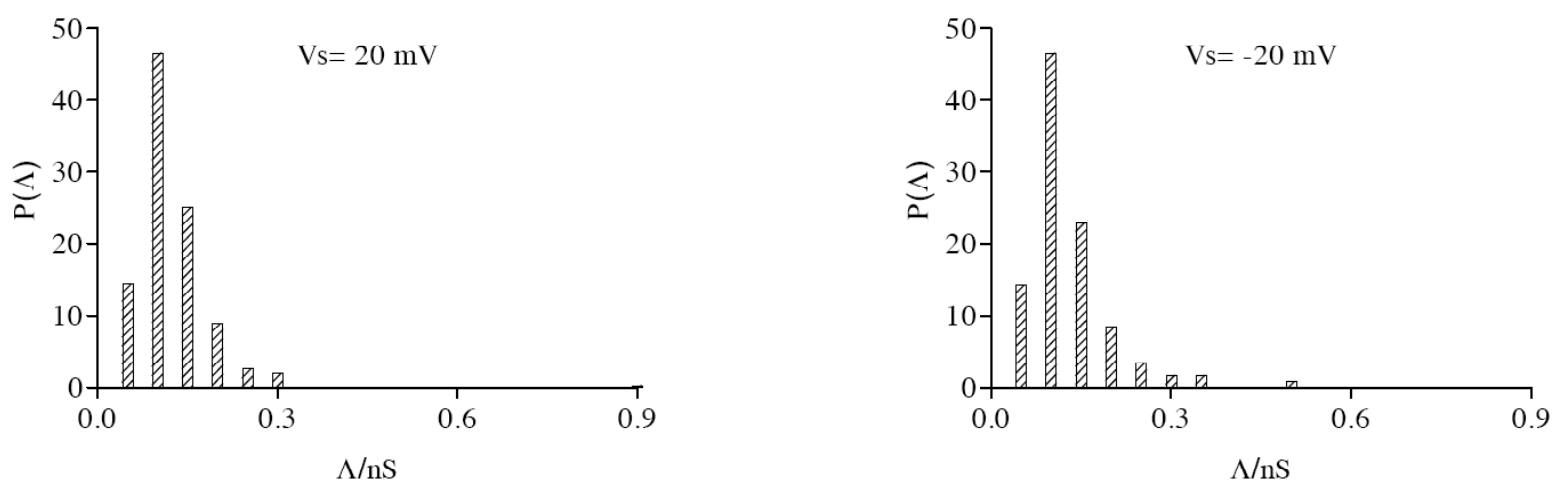

KPhosphate monobasic
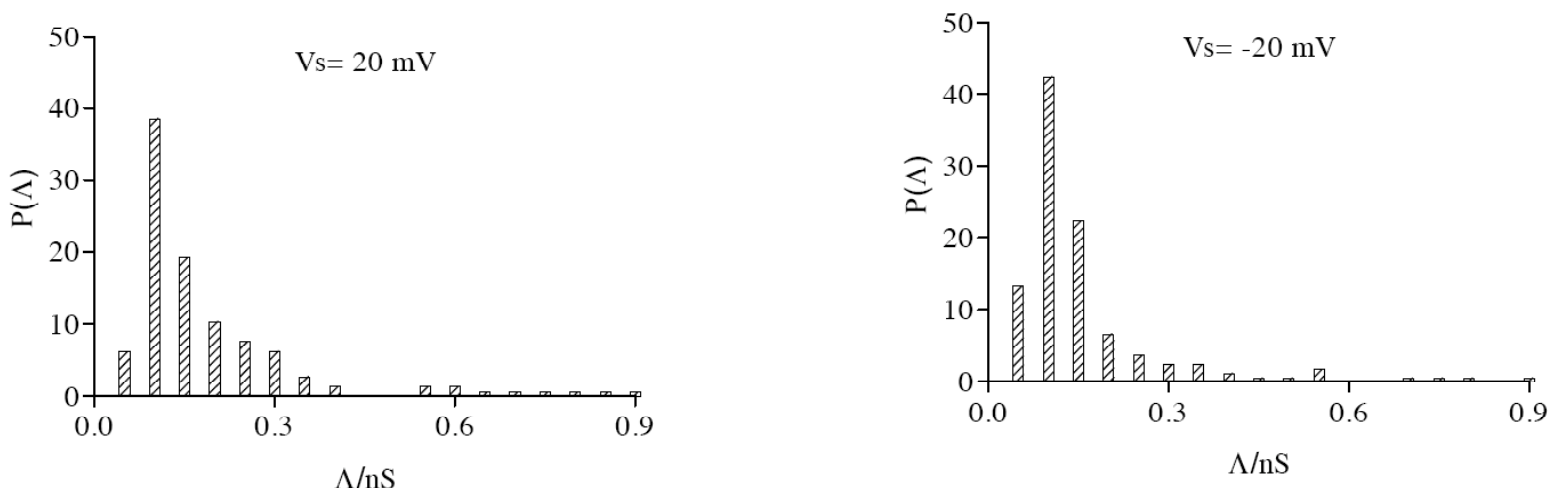

Fig. (4). Amplitude histograms of Kissper channel conductance. Histograms of the conductance fluctuations in the different salt solutions at applied voltages of $\pm 20 \mathrm{mV}$. Probability of the conductance, $\mathrm{P}(\Lambda)$, is the number of observed steps within an interval of width $(\Delta \Lambda=0.05 \mathrm{nS})$ divided by the total number of steps. The $P(\Lambda)$ values are indicated as a percentage. 
kissper channels are similar to those reported for other channel-forming peptides, in particular mammalian defensin [36], but also for synthetic peptides [37]. Two explanations may account for this: the channels may be formed by multimers of variable numbers of Kissper molecules, or else each multimer may have different conductance levels. The structure of the Kissper peptide makes it more likely that the channel is formed by oligomers rather than by a monomer. There are two possible models for channel formation: a- preexisting oligomers insert spontaneously into the PLM, or bKissper monomers first bind to the membrane and then diffuse laterally to form oligomers. Although we do not have direct evidence for the validity of these models, two orders of observation, i.e.: a- it was not possible to observe, in any of the different media used, conductance jumps for incubation times of the lipid-peptide mixture of less than five hours; b- on the other hand, the addition of Kissper to the medium after PLM formation and stabilization required longer activation times and higher activation voltages, as observed in our previous study [18], these considerations would give support to the first model.

The different diameters observed for kissper channels might depend on the number of oligomers that form the channel, as shown for other channel-forming peptides.

The conductance values obtained in the different salt solutions at different applied voltages indicate that kissper's channel-like pore shows a symmetry in $\mathrm{KCl}$ while in potassium gluconate, citrate and phosphate monobasic it shows an asymmetry when the applied voltages are \pm 40 and $\pm 60 \mathrm{mV}$. At these applied voltages, the kissper pore has a lower diameter than at $\pm 20 \mathrm{mV}$. The interactions between groups of salts and amino-acid residues are more evident when the channel lumen is narrower. In particular, potassium gluconate and phosphate monobasic can be considered donors of hydrogen bonds by means of the $-\mathrm{OH}$ groups to Asp residues. Potassium citrate can be considered both donor and acceptor of hydrogen bonds by means of the $\mathrm{COOH}$ : the $-\mathrm{C}=\mathrm{O}$ from the carboxylic groups can accept hydrogen bonds from Gly residues and the $-\mathrm{OH}$ from the carboxylic groups can donate hydrogen bonds to Asp residues. The kissper pore in potassium gluconate and phosphate monobasic shows a higher conductance at negative applied voltages $(-60 \mathrm{mV}$ and -40 and $-60 \mathrm{mV}$ respectively) than at positive voltages. The opposite happens in potassium citrate. It can be hypothesized that the $-\mathrm{OH}$ groups of both potassium gluconate and phosphate monobasic modulate the assembly of the Kissper channel-like pore when the polarity of the applied voltages is positive and the pore diameter is lower. The asymmetry of a channel indicates that it is a dipole with higher conductance at a polarity (positive or negative) of applied voltages than other. This property, found for the kissper channel, may be important for its putative biological activity.

A common property of bioactive peptides is the presence of a short $\alpha$-helical region that seems to play a key role in the interaction with membrane lipids. Indeed, Hoover and colleagues [35] showed that the $\alpha$-helical regions of hBD2 are important in the formation of the octamer and its orientation is conserved in the octamer core. Additionally, the dipoles of helices overlap to create a positively-charged region near the core.
The analysis of NOESY data obtained from Kissper are indicative of a short $\alpha$-helical region involving residues 3235 , in which residue 34 is the positively-charged histidine. Although we have no direct evidence of the channel conformation within the membrane, it can be hypothesized that the two Asp residues precede the short $\alpha$-helical regions of the kissper molecule to form the channel lumen, as shown for other bioactive peptides.

The second result of this study indicates that kissper pores shift selectivity from anions to neutral to cations, depending on the nature of the salt solutions. In $\mathrm{KCl}$ medium, $\mathrm{K}^{+}$interacts electrostatically with the negative charges of Asp residues, thus reducing its flux across the kissper channel as compared to $\mathrm{Cl}^{-}$. The potassium gluconate and phosphate monobasic molecules have a higher volume than $\mathrm{Cl}^{-}$and form hydrogen bonds to Asp residues. This may favour $\mathrm{K}^{+}$flux across the Kissper channel. The citrate molecule is not linear and has three carboxylic groups by which it can interact with the amino acids of kissper (Gly and Asp are donors of -OH bonds) thus reducing its flux across the kissper channel as compared to $\mathrm{K}^{+}$.

The results of this work suggest that a kissper action mechanism may be involved in the beneficial effects of kiwi on human health. We show that the Kissper peptide forms ion channels permeable to gluconate, citrate and phosphate monobasic, as well as to $\mathrm{Cl}^{-}$and $\mathrm{K}^{+}$, both of which are involved in some physiological processes. Potassium, the most abundant intracellular cation, is important for membrane transport, energy metabolism, fluid balance and proper cell functioning. Potassium plays a critical role in membrane polarization, and abnormal potassium homeostasis can result in disorders in cardiac, muscle and neurological function. Good sources of potassium include dairy products, fruits, vegetables, whole grains, nuts, seeds and dried beans [38]. Recent studies indicate that the potassium salts assumed with plant or animal foods are involved in divalent cation homeostasis e.g. calcium and magnesium, acid-base equilibrium, control of carbohydrate metabolism. Potassium organic anion salts, such as potassium citrate or potassium malate in plant foods, can exert alkalinizing effects after metabolization, with a potential for preventing the low-grade metabolic acidosis inherent in Westernized diet habits, as well as chronic pathologies such as osteopenia/osteoporosis or sarcopenia [39], while potassium also plays a protective role against hypertension stroke, cardiac dysfunction, renal damage, hypercalciuria, kidney stones and osteoporosis [21].

Kissper channel formation in DOPS:DOPE:DOPC PLMs, a surrogate of intestinal membrane, suggest a possible action of kissper, in particular, within the gastrointestinal tract promoting the absorption of substances beneficial to human health.

Wolffram and colleagues investigated the transport of tricarboxylates (citrate, tricarballylate) across the basolateral membrane isolated from the jejunum of rats. The reported data show that citrate uptake seems to be $\mathrm{Na}^{+}$-independent and not to be mediated by a carrier [40]. Kissper may therefore contribute directly to the laxative effect reported for kiwi fruit. In fact, some authors have speculated that the 
laxative effect of kiwi fruit may be dependent on individual nutrients other than on fiber [15].

\section{CONCLUSION}

This study shows that kissper, isolated from kiwi fruit, forms ion channels in PLMs, with composition similar to that of intestinal membrane, in $\mathrm{KCl}$, potassium gluconate, potassium citrate and potassium phosphate monobasic which are involved in some physiological processes.

In conclusion, our results indicate that kissper may be a novel nutrient with beneficial effects on human health and that channel formation may be a mechanism involved in its beneficial effects. The structural and functional features of kissper suggest that it could be a member of a new class of pore-forming peptides, with bioactive properties, that make it suitable for biotechnological and/or biological purposes. In fact, the compounds found in kiwi fruit show natural antioxidant capacity, antimicrobial and antifungal properties, potential antihypertensive and antithrombotic effects, enhancement of mineral absorption, and localized effects on the gut, all of which may help in the development of fruitbased functional and nutraceutical products.

\section{CONFLICT OF INTEREST}

Declared none.

\section{ACKNOWLEDGEMENTS}

The authors would like to thank Maria Antonietta Ciardiello for furnishing the Kissper peptide and Anthony Green for proofreading and providing linguistic advice.

\section{REFERENCES}

[1] Motohashi N, Shirataki Y, Kawase M, et al. Cancer prevention and therapy with kiwifruit in Chinese folklore medicine: a study of kiwifruit extracts. J Ethnopharmacol 2002; 81(3): 357-64.

[2] Collins BH, Horská A, Hotten PM, Riddoch C, Collins AR. Kiwifruit protects against oxidative DNA damage in human cells and in vitro. Nutr Cancer 2001; 39(1): 148-53.

[3] Collins AR, Harrington V, Drew J, Melvin R. Nutritional modulation of DNA repair in a human intervention study. Carcinogenesis 2003; 24(3): 511-5.

[4] Duttaroy AK, Jørgensen A. Effects of kiwi fruit consumption on platelet aggregation and plasma lipids in healthy human volunteers. Platelets 2004; 15(5): 287-92.

[5] Jung KA, Song TC, Han D, Kim IH, Kim YE, Lee CH. Cardiovascular protective properties of kiwifruit extracts in vitro. Biol Pharm Bull 2005; 28(9): 1782-5.

[6] Chang WH, Liu JF. Effects of kiwifruit consumption on serum lipid profiles and antioxidative status in hyperlipidemic subjects. Int J Food Sci Nutr 2009; 60(8): 709-16.

[7] Shirosaki M, Koyama T, Yazawa K. Anti-hyperglycemic activity of kiwifruit leaf (Actinidia deliciosa) in mice. Biosci Biotechnol Biochem 2008; 72(4): 1099-102.

[8] Yamazaki M, Mizoguchi H, Ohsawa M, Tseng LF, Suzuki T, Narita M. Implications of $\mathrm{Ca}(2+)$-activated $\mathrm{Cl}(-)$ channels in the delta-opioid receptor-mediated antinociception in the mouse spinal cord. Neurosci Lett 2000; 295(3): 113-5.

[9] Iwasawa H, Morita E, Yui S, Yamazaki M. Anti-oxidant effects of kiwi fruit in vitro and in vivo. Biol Pharm Bull 2011; 34(1): 128-34.

[10] Willis RBH, Lim JSK, Greenfield H. Composition of Australian foods: tropical and subtropical fruit. Food Technol Aust 1986; 38: 118-23.

[11] Szeto YT, Tomlinson B, Benzie IF. Total antioxidant and ascorbic acid content of fresh fruits and vegetables: implications for dietary planning and food preservation. Br J Nutr 2002; 87(1): 55-9.
[12] Tavarini S, Degli Innocenti E, Remorini D, Massai R, Guidi L. Antioxidant capacity, ascorbbic acid, total phenols and carotenoids changes during harvest and after storage of Hayward kiwifruit. Food Chem 2008; 107 (1): 282-8.

[13] Motohashi N, Shirataki Y, Kawase M et al. Biological activity of kiwifruit peel extracts. Phytother Res 2001; 15(4): 337-43.

[14] Rush EC, Patel M, Plank LD, Ferguson LR. Kiwifruit promotes laxation in the elderly. Asia Pac J Clin Nutr 2002; 11(2): 164-8.

[15] Chan AO, Leung G, Tong T, Wong NY. Increasing dietary fiber intake in terms of kiwifruit improves constipation in Chinese patients. World J Gastroenterol 2007; 13(35): 4771-5.

[16] Han KS, Balan P, Molist Gasa F, Boland M. Green kiwifruit modulates the colonic microbiota in growing pigs. Lett Appl Microbiol 2011; 52(4): 379-85.

[17] Tamburrini M, Cerasuolo I, Carratore V, et al. Kiwellin, a novel protein from kiwi fruit. Purification, biochemical characterization and identification as an allergen*. Protein J 2005; 24(7-8): 423-9.

[18] Ciardiello MA, Meleleo D, Saviano G, et al. Kissper, a kiwi fruit peptide with channel-like activity: structural and functional features. J Pept Sci 2008; 14(6): 742-54.

[19] Florack DE, Stiekema WJ. Thionins: properties, possible biological roles and mechanisms of action. Plant Mol Biol 1994; 26(1): 25-37.

[20] Brogden KA. Antimicrobial peptides: pore formers or metabolic inhibitors in bacteria? Nat Rev Microbiol 2005; 3(3): 238-50.

[21] Demigné C, Sabboh H, Rémésy C, Meneton P. Protective effects of high dietary potassium: nutritional and metabolic aspects. J Nutr 2004; 134(11): 2903-6.

[22] Micelli S, Meleleo D, Picciarelli V, Gallucci E. Effect of sterols on beta-amyloid peptide (AbetaP 1-40) channel formation and their properties in planar lipid membranes. Biophys J 2004; 86(4): 2231-7.

[23] Micelli S, Gallucci E, Meleleo D, Stipani V, Picciarelli V. Mitochondrial porin incorporation into black lipid membranes: ionic and gating contribution to the total current. Bioelectrochemistry 2002; 57(2): 97-106.

[24] Roland B. Analysis and chemical modification of bacterial porins New York and London: Plenum Press 1986; p. 20.

[25] Lalonde G, McDonald TV, Gardner P, O'Hanley PD. Identification of a hemolysin from Actinobacillus pleuropneumoniae and characterization of its channel properties in planar phospholipid bilayers. J Biol Chem 1989; 264(23): 13559-64.

[26] Vermeirssen V, Camp JV, Verstraete W. Bioavailability of angiotensin I converting enzyme inhibitory peptides. Br J Nutr 2007; 92: 357-66.

[27] Ryan JT, Ross RP, Bolton D, Fitzgerald GF, Stanton C. Bioactive peptides from muscle sources: meat and fish. Nutrients 2011;3(9): 765-91.

[28] Hartmann R, Meisel H. Food-derived peptides with biological activity: from research to food applications. Curr Opin Biotechnol 2007; 18(2): 163-9.

[29] Kitts DD, Weiler K. Bioactive proteins and peptides from food sources. Applications of bioprocesses used in isolation and recovery. Curr Pharm Des 2003; 9(16): 1309-23.

[30] Nagpal R, Behare P, Rana R, et al. Bioactive peptides derived from milk proteins and their health beneficial potentials: an update. Food Funct 2011; 2(1): 18-27.

[31] Erba D, Ciappellano S, Testolin G. Effect of the ratio of casein phosphopeptides to calcium (w/w) on passive calcium transport in the distal small intestine of rats. Nutrition 2002; 18(9): 743-6.

[32] Edmunds SJ, Roy NC, Love DR, Laing WA. Kiwifruit extracts inhibit cytokine production by lipopolysaccharide-activated macrophages, and intestinal epithelial cells isolated from IL10 gene deficient mice. Cell Immunol 2011; 270(1): 70-9.

[33] Bohlmann H, Clausen S, Behnke S, et al. Leaf-specific thionins of barley-a novel class of cell wall proteins toxic to plant-pathogenic fungi and possibly involved in the defence mechanism of plants. EMBO J 1988; 7(6): 1559-65.

[34] Froy O, Gurevitz M. Membrane potential modulators: a thread of scarlet from plants to humans. FASEB J 1998; 12(15): 1793-6.

[35] Hoover DM, Rajashankar KR, Blumenthal R, et al. The structure of human beta-defensin-2 shows evidence of higher order oligomerization. J Biol Chem 2000; 275(42): 32911-8. 
[36] Kagan BL, Selsted ME, Ganz T, Lehrer RI. Antimicrobial defensin peptides form voltage-dependent ion-permeable channels in planar lipid bilayer membranes. Proc Natl Acad Sci USA 1990; 87(1): 210-4.

[37] Oiki S, Danho W, Montal M. Channel protein engineering: synthetic 22-mer peptide from the primary structure of the voltagesensitive sodium channel forms ionic channels in lipid bilayers. Proc Natl Acad Sci USA 1988; 85(7): 2393-7.

[38] McGill CR, Fulgoni VL, DiRienzo D, Huth PJ, Kurilich AC, Miller GD. Contribution of dairy products to dietary potassium intake in the United States population. J Am Coll Nutr 2008; 27(1): 44-50.

[39] Sabboh H, Coxam V, Horcajada MN, Rémésy C, Demigné C. Effects of plant food potassium salts (citrate, galacturonate or tartrate) on acid-base status and digestive fermentations in rats. $\mathrm{Br} \mathrm{J}$ Nutr 2007; 98(1): 72-7.

[40] Wolffram S, Unternährer R, Grenacher B, Scharrer E. Transport of citrate across the brush border and basolateral membrane of rat small intestine. Comp Biochem Physiol Physiol 1994; 109(1): $39-52$.

(C) Meleleo et al.; Licensee Bentham Open.

This is an open access article licensed under the terms of the Creative Commons Attribution Non-Commercial License (http://creativecommons. org/licenses/ by-nc/3. 0/) which permits unrestricted, non-commercial use, distribution and reproduction in any medium, provided the work is properly cited. 